\title{
Espacios 100\% libres de humo: una realidad en el Distrito Federal
}

\author{
Xiuh Guillermo-Tenorio, Dip.(I)
}

E 126 de febrero de 2008, con la aprobación de las reformas a la Ley de Protección a la Salud de los No Fumadores en el Distrito Federal ${ }^{*}$ y la Ley para el Funcionamiento de Establecimientos Mercantiles, la conversión de todos los espacios públicos cerrados en áreas 100\% libres de humo, se marca un hito en la forma de diseñar políticas de prevención y salubridad en México: hasta entonces no se había hecho una reforma sanitaria que, entre otras bondades, tuviera un impacto positivo, directo e inmediato sobre las rutinas de socialización; pudiera disminuir eficazmente el consumo del tabaco ofreciendo resultados mesurables en el mediano plazo y en suma, aportara un elemento normativo para la sana convivencia social, al consolidar el ejercicio de un derecho fundamental común sobre las libertades individuales.

El presente trabajo expone el proceso legislativo por medio del cual se reformaron las citadas leyes y se crearon los espacios 100\% libres de humo de tabaco. Para tal efecto, la exposición se divide en cuatro partes: 1) una descripción de la situación del tabaquismo en México y en el mundo; 2) una justificación del porqué los espacios libres de humo son necesarios para combatir la adicción al consumo de tabaco; 3) los antecedentes que dieron origen a la reforma; y 4) el proceso legislativo

* Dicha ley se publicó en la Gaceta Oficial del Distrito Federal el 29 de enero de 2004. que concluyó con la consolidación de los espacios 100\% libres de humo en la capital del país.

\section{Consumo en México y el mundo}

Podemos afirmar que existe consenso entre todos los actores acerca del daño que ocasiona el consumo del tabaco. En principio, debemos reconocer al tabaquismo como una enfermedad crónica de alta reincidencia, relacionada con la adicción física y psicológica a la nicotina. Hoy sabemos que el humo de tabaco contiene más de 4000 sustancias químicas tóxicas y alrededor de 70 sustancias cancerígenas. De acuerdo con Health Consequences of Smoking. A Report of the Surgeon Gene$\mathrm{ral}$, la lista de las enfermedades relacionadas con el tabaquismo incluye, entre otros padecimientos, ataque al corazón; infarto cerebral; enfermedad pulmonar crónica; cáncer de pulmón, laringe, esófago, boca y vejiga. Una conclusión general del mencionado reporte es que "prácticamente no hay un órgano del cuerpo que no se vea afectado por el consumo activo del cigarro". ${ }^{1}$

A pesar de tales hallazgos, el consumo de tabaco no disminuye. La Organización Mundial de la Salud (OMS) señala que existen globalmente 1300 millones de fumadores, que en números gruesos equivalen al $30 \%$ de la población mundial adulta.

Las enfermedades vinculadas con el consumo del tabaco constituyen la principal causa de muerte prevenible, representando cerca de 5 millones de fallecimientos anuales; el tabaquismo causa más muertes que el sida, el alcoholismo, los accidentes automovilísticos, las dro-

(I) Coordinador de Asamblea Legislativa del Distrito Federal, Diputado Federal, México.

Fecha de aceptado: 28 de abril de 2008 Solicitud de sobretiros: Dip. Xiuh Guillermo Tenorio. Plaza Constitución 7, Centro Histórico, del. Cuauhtémoc, 06010, México, DF. Correo electrónico: gtenorio@asambleadf.gob.mx 
gas ilegales, los incendios, los homicidios y el suicidio combinados. ${ }^{2} \mathrm{Si}$ las tendencias continúan, para el año 2020 serán 10 millones de personas las que mueran anualmente a causa del tabaquismo, 70\% de los cuales habitarán países en vías de desarrollo.

El panorama en México, donde la prevalencia de consumo de tabaco es de $27 \%$, presenta una situación similar. La Cuarta Encuesta Nacional de Adicciones 2002 demuestra que hay 15 millones de fumadores activos y 48 millones de personas que viven expuestas involuntariamente al humo de tabaco. ${ }^{3}$ Esto provoca que, ya sea por consumo o por exposición al humo de segunda mano, 165 mexicanos mueran diariamente, cifra equivalente a 60000 muertes anuales, $11 \%$ del total nacional. ${ }^{3}$ De estos fallecimientos, $38 \%$ son atribuibles a padecimientos isquémicos del corazón; $29 \%$ a enfermedades pulmonares; $23 \%$ a enfermedades cerebro-vasculares y $10 \%$ a cáncer en vías respiratorias.*

Por si fuera poco, los hábitos de consumo de tabaco y la prevalencia del tabaquismo entre jóvenes son muy preocupantes.

La Encuesta Nacional sobre Tabaquismo entre Jóvenes, practicada en 2003 y en 2006 por el Instituto Nacional de Salud Pública (INSP) encontró, entre otras cosas, que 5 de cada 10 estudiantes ha probado cigarrillos alguna vez; que el consumo inicia a los 10 años de edad; que la prevalencia actual entre los 12 y los 15 años de edad aumentó de 20 a 25\% entre 2003 y 2006; y que en el Distrito Federal (DF) 53\% de los estudiantes fuma. La encuesta 2006 resalta que 6 de cada 10 fumadores jóvenes tienen acceso a cigarros y que tan sólo en el DF, 38.4\% de los jóvenes puede comprar cigarros, sin mayores contratiempos, a pesar de la prohibición de venta a menores.

Las estadísticas del tabaquismo dan una idea de su magnitud como problema de salud, y adquieren otro sentido dentro del contexto de las finanzas públicas.

Con base en estudios realizados por el INSP, se estima que el costo de la atención médica de enfermedades atribuibles al consumo de tabaco en el Instituto Mexicano del Seguro Social asciende a 7 mil millones de pesos anuales, lo que equivale al 5 por ciento del gasto total de operación de esa institución en 2004. En otras instituciones como la Secretaría de Salud, el costo de la atención de enfermedades atribuibles al tabaco podría representar al menos el 11 por ciento de su presupuesto. ${ }^{5}$

Además de los costos directamente asociados con el sistema de salud, el tabaquismo redunda en daños colaterales que lastiman a la sociedad en su conjunto.

\footnotetext{
* Secretaría de Salud e INEGI en 2004.
}

Reduce los años de vida productiva por incapacidad o muerte anticipada, produce ruptura familiar por muerte prematura, genera pérdidas económicas al reducir la fuerza laboral por enfermedad, y afecta el rendimiento académico y en general disminuye la calidad de vida de fumadores activos e involuntarios. ${ }^{6}$

\section{Importancia de los espacios libres de humo}

¿Por qué son tan importantes los espacios libres de humo? Hay una cifra en particular que los justifica plenamente: en México podemos atribuir 31000 fallecimientos anuales a la exposición crónica al humo de segunda mano.*

Recordemos que los espacios libres de humo fueron en su inicio una demanda laboral de los trabajadores de la industria de la hospitalidad en Estados Unidos: pilotos y sobrecargos en la industria de la aviación, personal de atención al público en hoteles y restaurantes. En ambos casos, la naturaleza de su trabajo implicaba estar expuestos permanentemente al humo de segunda mano, lo que acarreaba consecuencias perniciosas para su salud. No es casual que el primer espacio que se liberó del humo de cigarro haya sido el de los aviones comerciales. $^{7}$

A partir de esta experiencia es que los espacios libres de humo están considerados, por diversas instancias internacionales, como la medida más eficaz para combatir tanto el consumo del tabaco como los efectos causados por la exposición involuntaria al humo. Se ha demostrado que la restricción de fumar en lugares públicos, lugares de trabajo, restaurantes y bares disminuye el número de cigarros consumidos por los fumadores y los alienta a dejarlo. ${ }^{7}$

Por otra parte, se ha determinado que el humo de segunda mano contiene las mismas sustancias carcinógenas y los agentes tóxicos que inhalan directamente los fumadores. Según el reporte del Cirujano General de 2006, dentro de los riesgos para los no fumadores encontramos cáncer de pulmón y cardiopatías; asma; bronquitis; neumonía; infecciones del oído; trastornos en el desarrollo del feto, bajo peso al nacer, nacimientos prematuros y retraso del desarrollo en la niñez. Adicionalmente, se asocia con mayores tasas de síndrome de muerte súbita del lactante.

El porcentaje de la población expuesta al humo de segunda mano en México ha ido en aumento. En 1992, 41\% de la población era fumador involuntario; para 1998

\footnotetext{
* Dirección General de Epidemiología/Dirección General de Estadística e Informática, México, Secretaría de Salud, 2004.
} 
esta cifra aumentó a 52.6 por ciento. Las encuestas sobre tabaquismo entre jóvenes resaltan que en la Ciudad de México $49 \%$ de los jóvenes convive con fumadores en sus hogares; en el mismo sentido, casi $60 \%$ de los estudiantes encuestados están expuestos al humo de tabaco ambiental en espacios públicos. En particular, en la Ciudad de México 56.4\% de los estudiantes consideraron estar expuestos en lugares públicos.

En 2007, siguiendo un protocolo internacional utilizado en otros países latinoamericanos, se realizó un estudio en la Ciudad de México para evaluar la presencia de humo de tabaco ambiental en lugares públicos. Se colocaron monitores de nicotina en un hospital, dos escuelas, un edificio de oficinas públicas, un aeropuerto, siete restaurantes y tres bares durante dos semanas. Entre otros resultados, este estudio encontró que: 1) había nicotina en todos los lugares monitoreados, reflejando la falta de cumplimiento de la legislación; 2) la mera separación de áreas de fumar y no fumar no resultaba efectiva para controlar la exposición de los no fumadores al humo de cigarro; y 3) los bares de la Ciudad de México tenían, junto con los de Perú, las concentraciones de nicotina más altas de Latinoamérica. ${ }^{8}$

El conjunto de investigaciones médicas y sociales sumadas a las justas demandas laborales, justifican la necesidad de implementar acciones preventivas e integrales para controlar tanto el tabaquismo activo como los daños que causa la exposición involuntaria al humo del tabaco.

\section{Antecedentes en México}

Se ha dicho que las reformas a la Ley de Protección a la Salud de los No Fumadores son "producto de una moda". En realidad, y como ha sucedido en todas las ciudades en las que existen los espacios 100\% libres de humo, antes de su consolidación hubo polémica y debates en los que participaron todos los actores involucrados: comunidad médica, esfera política, sociedad civil, consumidores y empresarios.

Desde hace varios años, gobierno y sociedad mexicana han planteado diversas medidas de control de tabaco con la finalidad de reducir su consumo, así como campañas para prevenir e informar a la población sobre los riesgos que conlleva la adicción a la nicotina. Antes de las reformas en el DF ya existían y siguen vigentes prohibiciones a la venta de tabaco a menores de edad y ventas unitarias de cigarros; restricciones a la publicidad y patrocinio de productos de tabaco y prohibición a fumar en edificios públicos. Desafortunadamente, las estadísticas sugieren que las reglamentaciones no han sido del todo cumplidas.
Por otro lado, debe señalarse que antes de que aprobarse los espacios $100 \%$ libres de humo en el DF, éstos ya contaban con dos antecedentes directos e inmediatos.

El primero es el Convenio Marco para el Control del Tabaco, firmado por México el 12 de agosto de 2003 y ratificado por el Senado el 14 de abril de 2004. Dicho documento, auspiciado por la OMS, establece las mínimas medidas de control que habrán de aplicarse para reducir la prevalencia del consumo y la exposición al humo de tabaco. Sus disposiciones principales son las siguientes: garantizar el acceso a información; prohibir la venta de tabaco a menores; restringir acciones y contenidos publicitarios, promoción y patrocinio de los productos de tabaco; adoptar fuertes medidas impositivas en materia de precios, empaquetado y etiquetado; disminuir el tráfico ilícito de cigarros y garantizar la protección frente al humo de tabaco en el ambiente.

El segundo se encuentra en el trabajo que Diputados locales realizaron durante la LIX Legislatura. Los legisladores mexicanos por primera vez retomaron esta preocupación médica y social, colocando decisivamente el derecho a la salud de los no fumadores sobre la mesa. Durante esos años los legisladores locales impulsaron diversas medidas en pro de la protección de los no fumadores, aprobandose durante esa Legislatura reformas significativas referentes al control del tabaco en la Ley General de Salud.

Sin embargo, el proyecto tenía un alcance mayor, por lo que se presentó la Ley General para la Protección de la Salud de los Fumadores y No Fumadores, iniciativa que por su enfoque y alcances representaba un antes y un después en materia de legislación sanitaria en México. Dicha iniciativa se dictaminó en sentido negativo.

\section{Primera reforma: acuerdo político}

Los Diputados locales por el DF, dándole continuidad al proyecto en mención a favor de los no fumadores presentó la iniciativa por la cual se reformaban diversas disposiciones de la Ley de Protección a la Salud de los No Fumadores y de la Ley para el Funcionamiento de Establecimientos Mercantiles, ambas del DF. Su gran aportación fue colocar de nueva cuenta en el centro de la discusión la pertinencia de convertir todos los espacios públicos cerrados del DF en espacios 100\% libres de humo.

Por su parte, la Coalición Parlamentaria Socialdemócrata propuso algunas modificaciones adicionales, que incluían prohibir la publicidad del tabaco en el mobiliario urbano; prohibir su publicidad y venta en escuelas y prohibir la entrada de menores a establecimientos con licencia tipo "B" (que permiten la venta 
de alcoholes), excepto en eventos especiales para ellos ("tardeadas") con prohibición expresa de venta y consumo de tabaco durante los mismos.

En su turno, el Partido Acción Nacional propuso una iniciativa que pedía la adecuación de los establecimientos mercantiles para contar con espacios para no fumadores y fumadores, sujetos a que existiera entre ellos una separación física y sistemas de extracción en las áreas destinadas a fumadores.

Como resultado de una negociación política, el dictamen de la reforma original complementada por la propuesta socialdemócrata pudo aprobarse el 2 de octubre de 2007, pero no sin antes sufrir cambios sustanciales.

En la construcción de acuerdos en torno a esta reforma, la propuesta inicial de declarar a todo establecimiento mercantil cerrado como un área prohibida para el consumo de tabaco se modificó. En su lugar, se retomó la propuesta de aceptar una superficie de 30\% del local debería destinarse a los fumadores, a condición de que existiera una separación física y señalización entre ambas zonas, así como equipos purificadores de aire en el establecimiento.

Adicionalmente, se añadió al texto original una prohibición para vender cajetillas de cigarros en el interior de restaurantes.

Durante la preparación del reglamento, la Secretaría de Salud y la Consejería Jurídica del DF* concluyeron, en consulta con representantes de los restaurantes, que la propuesta era económicamente inadecuada y legalmente conflictiva. Fijar las condiciones en que se pudiese validar la separación, desde la medición del área hasta la adquisición de los equipos permitidos para habilitarla, resultaban casuísticas y representaban un alto costo para los negocios.

Por ello, ante recomendaciones de la autoridad, de asociaciones de prestadores de servicios y de empresas individuales, se retomó la intención original de declarar todos los espacios públicos cerrados como espacios 100\% libres de humo.

\section{Segundo paquete de reformas: consolidación}

Un punto de quiebre en este proceso fue la determinación de algunas cadenas de restaurantes de ampararse conjuntamente en contra de la primera reforma. Desde

\footnotetext{
* La facultad de reglamentar las leyes del Distrito Federal recae directamente en la oficina del Jefe de Gobierno del Distrito Federal, quien a su vez la delega en su Consejería Jurídica.
}

el punto de vista de la Cámara Nacional de la Industria Restaurantera, ${ }^{*}$ la separación física de los locales y la instalación de los extractores resultaba imposible de cumplir para la mayoría de sus afiliados. Para aquellos en condiciones de ajustarse a la legislación, la remodelación de los negocios implicaba inversiones millonarias, reducción de ventas e incluso, cerrar durante semanas. La interposición en diciembre de 2007 de un amparo por parte de la Operadora Vips y la obtención de la suspensión provisional correspondiente,, encendieron las alertas.

El nuevo paquete de reformas a la Ley de Protección a la Salud de los No Fumadores y a la Ley para el Funcionamiento de Establecimientos Mercantiles fue presentada por el partido Nueva Alianza apoyados por Diputados del PRD y el PRI

A diferencia de lo ocurrido durante la aprobación de la primera reforma, que generó cobertura mediática discreta, cuando la nueva iniciativa subió a la tribuna el tema ocupaba un lugar preponderante dentro de la agenda nacional y había suscitado un acalorado debate público no visto desde la despenalización del aborto en el DF, y que se magnificó con la discusión, en paralelo, de la Ley General para el Control de Tabaco, presentada en el Senado. $\$$

Son poco comunes los debates legislativos en los que la opinión pública, en todos sus niveles, participa con actividad e interés. Éste fue uno de ellos.

$\mathrm{Al}$ acercarse la llegada de los espacios 100\% libres de humo, diversas personalidades del ámbito público utilizaron sus espacios editoriales para escribir a favor y en contra de la medida. Los más se decantaron por la defenestración de la reforma y sus promotores. Personajes de valía y estima pública como periodistas y analistas políticos, fueron algunos de los muchos que entre enero y febrero escribieron contra los espacios libres de humo. Tres fueron sus recursos principales:

1. Los espacios libres de humo atentan contra los derechos y libertades de los fumadores,

2. Los espacios libres de humo son discriminatorios, atentan contra una minoría y violan el derecho

\footnotetext{
* CANIRAC, agrupación empresarial vinculada con la Cámara Nacional de Comercio (CANACO), y que reúne a más de 35000 establecimientos sólo en la Ciudad de México.

‡ La suspensión provisional en cuestión se otorgó específicamente a la prohibición a la venta de cigarros en el interior de restaurantes. El resto del amparo, incluyendo el recurso interpuesto en contra de las adecuaciones a los locales, fue desechado.

$\S$ Dicha Ley fue aprobada el 26 de febrero en el Senado. La publicación de este ordenamiento en el Diario Oficial de la Federación está pendiente.
} 
constitucional a la no discriminación;

3. La adopción de políticas restrictivas es propia de países anglosajones, incompatibles con la cultura mexicana;

Los espacios libres de humo no atentan en forma alguna contra el régimen constitucional. Por el contrario, el derecho a la salud está expresamente contemplado en el Artículo 25 de la Declaración Universal de los Derechos Humanos y en el Artículo 4ํㅜㄹ Párrafo $3^{\circ}$ de la Constitución Política de los Estados Unidos Mexicanos. Eso significa que esta reforma tiene por fin ontológico la consolidación de un derecho fundamental como la salud, y no hace sino fortalecer el estado de derecho en su conjunto. Desde el punto de vista jurídico y ético, éste es el eje articulador de la propuesta.

Ciertamente, los espacios libres de humo limitan una libertad de acción; en este caso, la libertad de fumar. Independientemente de que no existe el mal llamado "derecho a fumar", de que tampoco existe ordenamiento legal alguno que se le pueda asemejar, y que un teórico liberal tan influyente como Stuart Mill coincida en que el límite de la libertad es el daño a terceros, ${ }^{9}$ la consolidación del derecho a la salud es una acción legislativa que beneficia tanto a fumadores como a no fumadores.

Debe recalcarse que un derecho fundamental, a diferencia de una libertad individual, es irrenunciable. Por definición, los derechos no son sujetos de la "libertad de elección" que argumentan como defensa los fumadores. En otras palabras, si los fumadores no pueden renunciar a su derecho a la salud, mucho menos pueden, en nombre una libertad individual, exigir a terceros que lo hagan en los hechos.

Al equiparar a los derechos con las libertades, los defensores de los fumadores incurrían en una manipulación de conceptos que no guardan entre sí ninguna relación ética, lógica o jurídica. Algo similar ocurre cuando se apela a la discriminación como argumento en contra de los espacios 100\% libres de humo.

Textualmente, el Artículo 1ํㅜㄹ Párrafo $3^{0}$ de nuestra Constitución señala que: "Queda prohibida toda discriminación motivada por [...], las condiciones de salud $[\ldots]$ las preferencias [...] o cualquier otra que atente contra la dignidad humana y tenga por objeto anular o menoscabar derechos y libertades de las personas".

Indudablemente que el tabaquismo es una condición de salud y constituye una preferencia. Sin embargo, la discriminación se aplica sobre las personas, no sobre sus acciones. En otras palabras, sería discriminatorio que, por el hecho de fumar, se impidiera a los fumadores entrar en locales cerrados. Los espacios libres de humo, de hecho, anulan cualquier posibilidad de segregación, pues obligan a la convivencia pacífica entre fumadores y no fumadores, algo de lo que adolece el llamado "modelo español", con locales exclusivos para fumadores.

Finalmente, suponiendo que la medida fuera representativa de la cultura anglosajona y que estuviese absolutamente en contra de la nuestra, ¿cómo se explica que dos investigaciones de opinión diferentes, conducidas durante el mes de febrero por los periódicos $E l$ Universal $^{*}$ y Excélsior, ${ }^{\ddagger}$ así como una tercera realizada en octubre de 2007 por la casa encuestadora Parametría, $\$$ hayan coincidido en que 8 de cada 10 mexicanos apoyaba las medidas a favor del control del tabaco? Éste no es un dato menor si consideramos que, como ya se menciono previamente, $27 \%$ de los mexicanos fuma o que incluso un régimen como el de Fidel Castro suscribió el Convenio Marco y participó activamente en diversas campañas antitabaco de la isla.

A pesar de la gran simpatía ciudadana despertada por los espacios $100 \%$ libres de humo, con el paso de los días se tensó el debate mediático en el cual participaron activamente diputados del Partido Alternativa Socialdemócrata, en defensa de los fumadores; y diputados del PRD, quien propuso una segunda iniciativa de contenido marcadamente pro fumador, la cual fue desechada.

El 25 de febrero se presentó ante comisiones unidas de Salud y Administración Pública Local el Dictamen que sería votado en el pleno. Si bien había claridad en que el voto de PAN, PRI y Nueva Alianza era a favor del dictamen, el sentido de los votos del PRD era incierto, ello a pesar del apoyo abierto del, líder del perredismo en la Asamblea, daba a la reforma. En la discusión en comisiones sólo dos diputados expusieron oposición al dictamen, argumentando en su contra fallas técnicas, sesgo en su contenido y cambios no consensuados. Al finalizar la reunión, el resultado permitía prever lo que ocurriría en el pleno: 16 votos a favor, uno en contra, tres abstenciones.

El debate de la sesión extraordinaria del 26 de febrero de 2008 fue una repetición de la discusión mediática

\footnotetext{
* Encuesta en el DF publicada por El Universal el 14 de febrero de 2008. Porcentaje agregado de respuestas a la pregunta “¿Está usted a favor o en contra del la ley antitabaco?": $78 \%$ de acuerdo, $12 \%$ en desacuerdo, $10 \% \mathrm{NS} / \mathrm{NC}$.

‡ Encuesta nacional publicada por Excélsior el 18 de febrero 2008. Por-

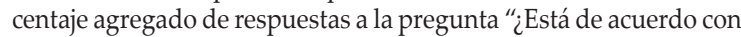
que se prohíba fumar en lugares públicos como restaurantes, bares, y centros educativos?": $81 \%$ de acuerdo, $19 \%$ en desacuerdo.

$\S$ Encuesta en el DF realizada por Parametría durante octubre de 2007. Porcentaje agregado de respuestas a la pregunta “Está usted de acuerdo o en desacuerdo con una iniciativa que prohíba fumar en todos los lugares públicos cerrados?": $80 \%$ de acuerdo, $14 \%$ en desacuerdo, $6 \% \mathrm{NS} / \mathrm{NC}$.
} 
que durante 60 días previos condujeron promotores y detractores de la medida. Después de más de tres horas de intervenciones, con más de 40 votos de diputados del PRD, PAN, PRI, Nueva Alianza e incluso de la Coalición Parlamentaria Socialdemócrata, ${ }^{*}$ se aprobó el dictamen por el que se reformaban la Ley para la Protección de los No Fumadores y la Ley para el Funcionamiento de Establecimientos Mercantiles, ambas del Distrito Federal. Las modificaciones entraron en vigor el 3 de abril, con su publicación en la Gaceta Oficial del Distrito Federal. (Ver Anexo 2)

A pesar del apoyo social que respalda a la reforma y de su solidez dentro del marco constitucional, un grupo encabezado por diputados opuestos a la nueva ley interpuso amparos en contra de la ley. Si bien al escribir estas líneas dicho proceso apenas daba inicio, se puede pronosticar que las demandas se desecharán por razones jurídicas como las que a continuación se comentan:

Tratándose de derechos fundamentales regulados bajo un sistema de facultades concurrentes como la protección de la salud (Artículo $4^{\underline{0}}$ constitucional), las entidades federativas pueden regular las materias incluidas en leyes generales o federales siempre que, avanzando en el sentido marcado por la Constitución, otorguen mayores garantías. Dicha determinación fue establecida vía jurisprudencia de la Suprema Corte de Justicia en materia de educación para el DF y resulta aplicable por analogía a la salud. ${ }^{\ddagger}$

Serían entonces dos las condiciones para considerar constitucional una legislación local que dispone una regulación diversa a la establecida en la ley superior: 1) que coincida con los principios establecidos en la Constitución y la ley marco aplicable y; 2) que agregue a los derechos fundamentales regulados.

Las reformas a la Ley de Protección a la Salud de los No Fumadores en el Distrito Federal satisfacen ambas condiciones:

1. La ampliación a $100 \%$ de los espacios libres de humo concuerda con los principios de protección a la salud consagrados en el Artículo $4^{\circ}$ constitucional y con diversas disposiciones de la Ley General de

\footnotetext{
* La Coalición Parlamentaria Socialdemócrata de la ALDF está compuesta por dos Diputados de Alternativa, uno del Partido del Trabajo, dos del PVEM y uno de Convergencia; los tres últimos avalaron con su voto los espacios $100 \%$ libres de humo en el DF.

$\ddagger$ Jurisprudencia visible en el Semanario Judicial de la Federación y su Gaceta XV, de enero de 2002, página 1035 y 1037.

$\S$ Específicamente Artículo 2을 Fracciones III y IV, y Artículo 6으, Fracciones VI y VII, ambos de la Ley General de Salud.
}

\section{Salud. $\$$}

2. Los espacios libres de humo agregan a la protección de la salud de fumadores, no fumadores y trabajadores de establecimientos mercantiles, por encima de la legislación marco establecida en la Ley General para el Control de Tabaco.

3. En el mismo sentido, la Ley General de Salud, tal como quedó reformada por la Ley General para el Control del Tabaco, dice en sus Artículos $3^{\circ} \mathrm{y}$ $13^{\text {avo }}$ que la prevención de enfermedades derivadas del tabaquismo le corresponde a las entidades federativas.

No deja de sorprender que, a pesar de toda la evidencia médica disponible y el apoyo social que los acompaña, los espacios $100 \%$ libres de humo hayan suscitado tan ardiente oposición. Al mismo tiempo, la naturaleza, ulterior desarrollo y conclusión de este debate son muestra palpable de las virtudes de la democracia liberal y los regímenes constitucionales consolidados.

Los espacios 100\% libres de humo en el DF son resultado de una iniciativa legislativa cuya maduración tomó varios años y que, antes de ser aprobada, debió consensuar intereses con los diversos sectores involucrados: empresas tabacaleras, empresarios de la industria de la hospitalidad, sector salud y sociedad civil.

Posteriormente, la discusión de la reforma derivó en modificaciones de fondo a la ley original, en las que se planteó y finalmente aprobó la conveniencia de contar con áreas exclusivas para fumadores. La nueva medida buscaba un mejor equilibrio entre interés público y ejercicio de derechos y libertades.

Sin embargo, dichas modificaciones resultaron improcedentes en el terreno práctico, por lo que la misma autoridad propuso regresar al modelo original.

El regreso a los espacios 100\% libres de humo provocó una movilización activa de parte de grupos de no fumadores, que en todo momento fueron respetados y escuchados, y a cuyas inquietudes se sumaron, haciendo válidas sus atribuciones como representantes populares, diversos diputados locales identificados con corrientes de izquierda, quienes acordes con sus principios ideológicos e independientemente de la probable pertinencia de sus argumentos, con toda libertad abogaron por un mayor respeto y tolerancia hacia los fumadores, quienes representan a una minoría.

Incluso, una vez que la ley fue aprobada, este grupo decidió hacer válidos sus derechos y recurrir a la protección de las autoridades, amparándose contra una ley que, a su juicio, lesiona sus intereses y lastima su libre albedrío.

Para la mayoría, simpatizante de la medida, los espacios $100 \%$ libres de humo garantizan positivamente 
su derecho a la salud. Incluso para sus detractores, el saldo final es muy positivo: es un ejemplo claro y sencillo de cómo la Soberanía Legislativa puede, a través de la modificación de una ley, fortalecer el estado de derecho y garantizar con acciones concretas el respeto al marco constitucional vigente y la acción del estado en beneficio de todos. Ésa es la gran enseñanza que deja tras sí la reforma a la Ley de Protección a la Salud de los No Fumadores en el Distrito Federal.

Sin embargo, el trabajo no está terminado. La experiencia durante las primeras semanas de existencia de los espacios $100 \%$ libres de humo es consistente con los resultados de las encuestas de opinión: tanto ciudadanos como restauranteros se han sumado al nuevo ordenamiento y durante su aplicación se han registrado pocos incidentes, ninguno grave. Eso hace prever que la consolidación de los espacios 100\% libres de humo como parte de las rutinas de socialización no representará problema alguno.

Aun así, la vigencia de la Ley para la Protección de la Salud de los No Fumadores depende en enorme medida del compromiso de los ciudadanos y de activismo para proteger y hacer valer sus derechos. En lo que respecta a la autoridad, está obligada a dar seguimiento, en todo sentido, al cumplimiento de las leyes y sus reglamentos en los restaurantes. Finalmente, en el caso de los legisladores, debemos estar pendientes de la evolución de esta política pública vigilando su cumplimiento, evaluando su aceptación ciudadana y mejorándola siempre que en ello no se altere ni su fin último ni su espíritu.

\section{Referencias}

I. U S Department of Health and Human Services (USDHHS). The health consequences of smoking: A Report of the Surgeon General. Atlanta (GA): U S Department of Health and Human Services. Centers for Disease Control and Prevention. National Center for Chronic Disease Prevention and Health Promotion, Office on Smoking and Health; 2004. 2. McGinnis JM, Foege WH. Cuasas de muerte en los Estados Unidos. JAMA 1993;270:2207-22I2.

3. Consejo Nacional Contra las Adicciones. Cuarta Encuesta Nacional de Adicciones - Tabaco, Alcohol y Drogas llegales. México: CONADIC, 2003. 4. Valdés-Salgado R, Reynales-Shigematsu LM, Lazcano-Ponce $E$, Hernández-Ávila M. Antes y después del Convenio Marco en México: una comparación desde la Encuesta sobre Tabaquismo en Jóvenes 2003 y 2006. Salud Publica Mex 2007;49 supl 2:SI55-SI69.

5. Reynales-Shigematsu LM, Rodríguez-Bolaños RA, Jiménez JA, JuárezMárquez SA, Castro-Ríos A, Hernández-Avila M. Costos de la atención médica atribuibles al consumo de tabaco en el Instituto Mexicano del Seguro Social. Salud Publica Mex 2006;48 supl I:S48-S64.

6. Belén Sáenz de Miera Juarez Jorge Alberto Jiménez Ruíz Luz Myriam Reynales Shigematsu. La Economía del tabaco en México.2007 7. US Department of Health and Human Services. The health consequences of involuntary exposure to tobacco smoke: A report of the Surgeon General. Atlanta, GA, USA, 2006. Disponible en: http://www. surgeongeneral.gov/library/secondhandsmoke

8. Barrientos-Gutiérrez T, Valdés-Salgado R, Reynales-Shigematsu LM, Navas-Acien A, Lazcano-Ponce E. Exposición involuntaria al humo de tabaco en lugares públicos de la Ciudad de México. Salud Publica Mex 2007;49 supl 2:S205-S2I2.

9. Stuart-Mil J. Sobre la libertad. Granica, 2004. 